\title{
Multiple Cell Populations in the Early Postnatal Subventricular Zone Take Distinct Migratory Pathways: A Dynamic Study of Glial and Neuronal Progenitor Migration
}

\author{
Satoshi 0. Suzuki and James E. Goldman \\ Department of Pathology and the Center for Neurobiology and Behavior, Columbia University, New York, New York 10032
}

\begin{abstract}
Neural progenitors in the subventricular zone (SVZ) of the postnatal rat forebrain give rise to either olfactory interneurons or glia. To investigate the overall patterns of progenitor movement, we labeled neonatal rat SVZ cells by stereotactic injection of a GFP-encoding retrovirus into the SVZ at various coronal levels. We then studied the movements of labeled cells by time-lapse videomicroscopy in living brain slices cut in different orientations. We observed two migration patterns: (1) progenitors migrated radially into the overlying white matter and cortex, but only at the level of viral injection; these were previously shown to give rise to astrocytes and oligodendrocytes, (2) progenitors migrated in a bidirectional, rostrocaudal pattern along the entire extent of the SVZ; many of these cells eventually migrated into the olfactory bulb and developed into interneurons, but they did not turn to migrate radially out of the SVZ until they reached the olfactory bulb. Video imaging showed apparent boundaries to migration between the SVZ and adjacent structures. These observations indicate that there are at least two distinct migratory pathways within the SVZ used differentially by immature neurons and glia.
\end{abstract}

Key words: subventricular zone; neural progenitor; migration; olfactory bulb; radial glia; time-lapse video imaging

\section{Introduction}

In the postnatal rat forebrain, neural progenitors in the subventricular zone (SVZ) give rise to glia and olfactory interneurons. Most of gliogenesis takes place in the perinatal period (Levison et al., 1993; Luskin and McDermott, 1994; Zerlin et al., 1995). During this time, progenitors migrate radially out of the SVZ into the overlying white matter and cortex, or first laterally through the white matter and then radially into the lateral cortex and striatum to develop into astrocytes and oligodendrocytes (Levison et al., 1993; Luskin and McDermott, 1994; Zerlin et al., 1995; Zerlin and Goldman, 1997). These migration pathways take place primarily in a coronal plane and are reminiscent of prenatal neuronal migration along radial glial processes (Bayer et al., 1991; Misson et al., 1991; de Carlos et al., 1996). Glial progenitors are also thought to use radial fibers as a preferential scaffold (Zerlin et al., 1995).

The anterior part of the SVZ (SVZa) has been considered a specialized compartment that generates neuroblasts that migrate anteriorly into the olfactory bulbs along the rostral migratory stream (RMS) to develop into olfactory interneurons (Luskin, 1993). Thus, previous observations suggest two distinct migration patterns of SVZ cells: radial (coronal) in the posterior and

Received 0ct. 16, 2002; revised Feb. 20, 2003; accepted March 3, 2003.

This work was supported by National Institutes of Health Grant NS17125 (J.E.G.). We thank Drs. Peter Canoll, Carol Mason, Merielba Zerlin, Ana Milosevic, and Christine Marshall for critically reading this manuscript and for insightful discussions. We are grateful to Dr. Akiyoshi Kakita for his extended suggestions on video imaging procedures. We thank Dr. Carol Mason for graciously sharing imaging equipment, Drs. Steve Suhr and Theo Palmer for generously providing the retroviral packaging cell line, and Dr. Bill Stallcup for kindly providing the NG2 antibody. We also thank J. J. Marshall for an intense instruction on video image editing, and Theresa Swayne and Sudhi Swamy for confocal image processing.

Correspondence should be addressed to Dr. Satoshi 0 . Suzuki at his present address: Department of Neuropathology, Neurological Institute, Kyushu University Graduate School of Medical Sciences, 3-1-1 Maidashi Higashi-ku, Fukuoka 812-8582, Japan. E-mail: sosuzuki@np.med.kyushu-u.ac.jp.

Copyright $\odot 2003$ Society for Neuroscience $\quad 0270-6474 / 03 / 234240-11 \$ 15.00 / 0$ tangential (rostrocaudal) in the anterior region of the forebrain, correlating with glial or neuronal fates, respectively.

However, it remains to be clarified how glial and neuronal progenitors are distributed along the rostrocaudal extent of the neonatal SVZ and how these populations are segregated in each path. Furthermore, in juvenile and adult rodents, a tangential migration of neuronal progenitors along the entire rostrocaudal extent of the lateral ventricular wall has been proposed (Lois and Alvarez-Buylla, 1994; Doetsch and Alvarez-Buylla, 1996). Whether or how this tangential path changes in distribution from the neonatal into the adult period remains unclear. To address these questions, we labeled dividing SVZ cells in the neonatal rat by stereotactic injection of a green fluorescent protein (GFP)encoding retrovirus into various parts of the SVZ. We then studied the migratory behavior of the labeled cells by observing their distribution in fixed tissue sections at various times as well as by time-lapse videomicroscopy on living brain slices cut in different orientations. Our observations indicate: (1) both olfactory interneurons and glia arise from the entire rostrocaudal extent of the SVZ including the RMS, and (2) gliogenic and neurogenic populations follow distinct migratory pathways.

\section{Materials and Methods}

Retrovirus stock and injection. Concentrated GFP-retrovirus stock, with a titer of $1-2 \times 10^{6} \mathrm{cfu} / \mathrm{ml}$ assayed with NIH3T3 cells, was produced as described previously (Kakita and Goldman, 1999). The virus plasmid, pNIT, contains a cDNA fragment of enhanced green fluorescent protein (EGFP) downstream of the tetracycline operon enhancer-promoter. Virus particles were collected from the culture supernatant after transient transfection of vesicular somatitis virus G-protein into nonconfluent cultures of the packaging cell line that stably expressed pNIT-EGFP. Stereotactic surgery and retrovirus injections into the SVZ were performed as described elsewhere (Levison et al., 1993; Zerlin et al., 1995; 

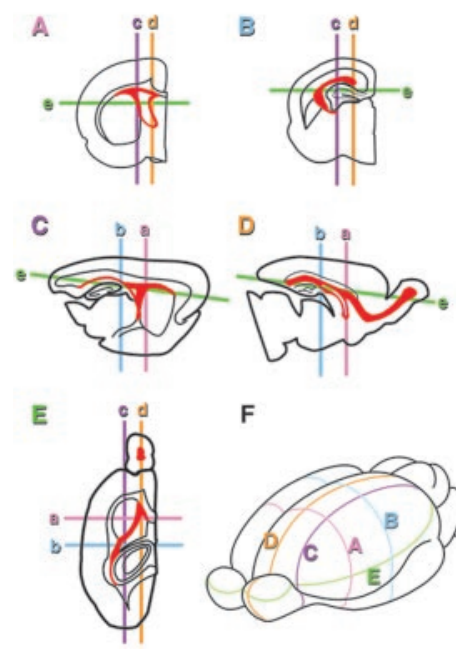

F

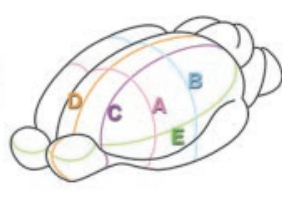

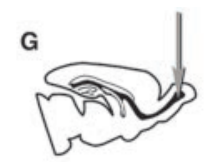

H

\section{I}
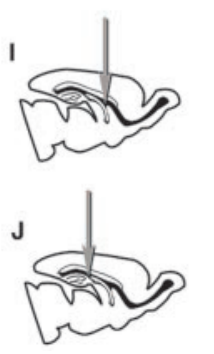
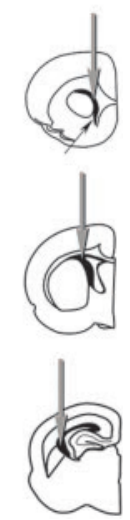

Figure 1. Spatial extent of the SVZ and planes along which brains were sectioned $(A-F)$ and stereotactic coordinates and injection sites $(G-J)$. $A-E$, The SVZ is indicated by red in each section. The planes of other sections relative to the one shown are indicated by lowercase letters in each section. $A$, Coronal section at the level of the septal nuclei. $B$, Coronal section at the level of rostrodorsal hippocampi. C, Lateral sagittal section at the level of the striatum. D, Medial sagittal section at the level of the septal nuclei and the RMS.E, Horizontal section at the level of the striatum. F, Anterolateral view of the whole brain showing the five planes of section. G-J, Sites of injection shown in sagittal planes and coronal planes are depicted on the left and right, respectively. $G$, Olfactory bulb injection. Virus was placed at a depth of $0.8 \mathrm{~mm}$ from the center of the dorsal surface of the olfactory bulb. $H$, Rostral injection; $2.0 \mathrm{~mm}$ anterior, $0.9 \mathrm{~mm}$ lateral to the bregma at a depth of $2.5 \mathrm{~mm}$. Arrow in the coronal plane indicates the vertical limb of the RMS. I, Middle injection; $0.7 \mathrm{~mm}$ anterior, $1.9 \mathrm{~mm}$ lateral to the bregma at a depth of $1.9 \mathrm{~mm}$. J, Caudal injection; $0.7 \mathrm{~mm}$ posterior, $2.1 \mathrm{~mm}$ lateral to the bregma at a depth of $2.0 \mathrm{~mm}$.

Kakita and Goldman, 1999). In this study, we designed a set of stereotactic coordinates to allow us to label SVZ cells at several different rostrocaudal levels. Each coordinate was calculated based on an atlas of embryonic day 22 (E22) rat embryonic brain (Altman and Bayer, 1995) followed by subtle adjustments by making test injections into postnatal day $0(\mathrm{P} 0)-\mathrm{P} 3$ rat brain with $1 \mu \mathrm{l}$ of trypan blue dye $(0.4 \%$, Invitrogen, Gaithersburg, MD) and immediately removing and dissecting the brains. Brains injected at P0 and P3 showed similar distributions and fates of labeled cells 4 weeks after each injection. Thus, data were collected from brains injected from P0 to P3. Injection sites and their coordinates used in this study are shown in Figure $1 G-J$. All the coordinates were designed to place the virus in the rostrocaudal extension of the dorsolateral SVZ. Caudal, middle, and rostral coordinates correspond to the dorsorostral hippocampi, the septal nuclei level, and the SVZa just at the beginning of the vertical limb of the RMS (Luskin, 1993), respectively. The middle injection has the same coordinates that we have used in previous studies (Levison et al., 1993; Zerlin et al., 1995; Kakita and Goldman, 1999). Sprague Dawley pups at P0-P3 were deeply anesthetized by immersion in ice water, positioned in a stereotactic apparatus, and $1 \mu \mathrm{l}$ of the retrovirus stock solution was injected either unilaterally or bilaterally. The protocol was approved by the Institutional Animal Care and Use Committee of Columbia University.

Slice culture and time-lapse image acquisition. Time-lapse image acquisitions of GFP-labeled living cells were performed on slices cut in coronal, sagittal, or horizontal orientation on the third day after injection (P3-P6), as described elsewhere (Kakita and Goldman, 1999). Briefly, rats were anesthetized by immersion in ice-cold water, and brains were removed. Coronal, sagittal, or horizontal slices were cut at $250 \mu \mathrm{m}$ thickness on a MacIlwain tissue chopper. The slices were then cultured with Eagle's Basal Medium with Earle's salts (BME; Invitrogen) supplemented with $18.6 \mathrm{~mm} \mathrm{NaHCO}_{3}, 1 \%$ BSA (fraction 5; Sigma, St. Louis, MO), 5 $\mu \mathrm{g} / \mathrm{ml}$ insulin, $5 \mu \mathrm{g} / \mathrm{ml}$ transferrin, $5 \mu \mathrm{g} / \mathrm{ml}$ sodium selenite (Sigma), 20 $\mathrm{U} / \mathrm{ml}$ penicillin-streptomycin (Invitrogen), 2 mM L-glutamine (Invitro- gen), $27 \mathrm{~mm}$ glucose, and $7.9 \mathrm{~mm} \mathrm{NaCl}$. Time-lapse video recordings were performed with a Zeiss (Oberkochen, Germany) Axiovert $35 \mathrm{M}$ with a mercury lamp, a silicon-intensified target camera (Hamamatsu, Tokyo, Japan), and a digital image processor (Metamorph; Universal Imaging, West Chester, PA) at low magnification using a $10 \times$ dry objective lens. Images were taken every 3 min over a period of $4-25 \mathrm{hr}$. Image analyses were performed using Adobe Photoshop 6.0 and Adobe After Effects 5.5 (Marshall and Saeed, 2002) software. Cell movements were traced using the motion tracking function of Adobe After Effects. The brightest part of each cell body was used as the tracking target. Tracking was started from a time point when a cell first came into focus or appeared at the edge of the imaging field until it either went out of focus or left the imaging field. Thus, some cells were tracked throughout the imaging period while others were tracked during various periods in which they were only clearly visible. All the traced paths were superimposed on the last frame of each imaging session. Note that the tracking lines therefore show positions of migratory courses relative to the structures in each slice, but do not indicate velocity of each cell because progenitors migrate in a saltatory manner (Kakita and Goldman, 1999) and not all cells were imaged in the same time window.

Histology and immunohistochemistry. To chart mass movements of cells, brains were fixed after retroviral injections. Animals were anesthetized by intraperitoneal injection of ketamine (Aveco, Ft. Dodge, IA; 75 $\mathrm{mg} / \mathrm{kg}$ ) and xylazine (Mobay, Shawnee, $\mathrm{KS} ; 5 \mathrm{mg} / \mathrm{kg}$ ) and were transcardially perfused with $\mathrm{PBS}$, followed by $4 \%$ paraformaldehyde in $0.1 \mathrm{M}$ phosphate buffer, $\mathrm{pH} 7.4$, at 1, 3, 5, or $28 \mathrm{~d}$ after injection. The brains were postfixed in the same fixative at $4^{\circ} \mathrm{C}$ overnight. Serial coronal, sagittal, or horizontal sections were cut at $100 \mu \mathrm{m}$ thickness on a Vibratome (Technical Products International, Series 100), collected in PBS, and stored at $4^{\circ} \mathrm{C}$ until use. Immunohistochemistry was performed on freefloating sections using the following primary antibodies. GFP (1:500; Molecular Probes, Eugene, OR), vimentin (1:100; clone v9; Dako, Carpinteria, CA), phosphorylated neurofilament (1:1000; clone SM31; Sternberger Monoclonals), GFAP (1:100; clone GA5; Roche Products, Hertfordshire, UK), and NG2 (a generous gift from Dr. William Stallcup, San Diego, CA). Sections were incubated overnight at $4^{\circ} \mathrm{C}$ in primary antibodies diluted in 1\% Triton X-100 and 10\% normal goat serum in PBS. Secondary antibodies were diluted in 5\% normal goat serum in PBS and reacted overnight at $4^{\circ} \mathrm{C}$. Retrovirally and/or immunohistochemically labeled sections were viewed by a laser-scanning confocal microscope (Zeiss LSM410), and three-dimensional reconstructions of Z-series images were performed when necessary. Alternatively, sections were viewed by Zeiss Axioplan microscope with epifluorescence optics, and digital images were acquired with an Axio digital camera (Zeiss) linked to OpenLab image acquiring software (Improvision, Lexington, MA). All the histological experiments, including video imaging, were repeated with at least three different pups.

Throughout the study, the injection site was confirmed by the densest GFP-labeled spot within the SVZ. Samples were excluded from analysis when the injection site was away from that previously determined by test injections with trypan blue, or the sample was injected into the lateral ventricle, indicated by GFP-labeled cells in the choroid plexus.

\section{Results}

We investigated the migratory patterns of neural progenitors within and out of the SVZ in fixed tissue and living brain slices cut in sagittal, coronal, and horizontal planes throughout the extent of the SVZ after retroviral injection into various parts of the SVZ (see above and Fig. 1).

\section{Neonatal SVZ progenitors migrate along the entire rostrocaudal extent of the SVZ}

To study the rostrocaudal limits of cell migration, neonatal brains were injected with GFP-retrovirus using either caudal (five hemispheres from four pups) or middle coordinates (four hemispheres from three pups) and were examined in sagittal planes. Figure $1 A-F$ shows representative levels in each sectioning orien- 
tation used in this study: the SVZ is labeled with red, and the spatial relationships among the various planes of section are indicated in Figure $1 F$. At $3 \mathrm{~d}$ after a caudal injection, labeled cells had migrated along the SVZ both rostrally and caudally from the injection site for a long distance, covering virtually the entire rostrocaudal extent of the SVZ, from the RMS to the caudal tip of the SVZ at the hippocampal border (Fig. 2A, arrowhead). By $5 \mathrm{~d}$ after injection (dpi), cells had migrated out of the RMS and dispersed in the olfactory bulb (Fig. $2 B$ ). At the caudal end of this pathway, migration appeared to stop at the most caudal tip of the SVZ (Fig. $2 A, B$, arrowhead). We never observed cells turning toward the hippocampal SVZ and migrating into the hippocampus. Horizontal sections demonstrated the long distance rostrocaudal migration along the SVZ adjacent to the striatum ( $n=3$, each after caudal and middle injection) (Fig. 3). This part of the SVZ corresponds to the striatal SVZ previously studied in coronal slices (Kakita and Goldman, 1999) and is continuous rostrally with the RMS at more ventral levels (data not shown). Thus, the striatal SVZ is included in the rostrocaudal stream along the ventricular surface toward the olfactory bulb (see Fig. 11D). This rostrocaudal pathway was therefore bordered dorsally by the SVZ-white matter interface, laterally by the SVZ-striatum interface, and caudally by the hippocampal boundary. A similar and extensive tangential migration was observed after a "middle" injection (data not shown).

\section{The dorsal radial migration path is primarily confined to a coronal plane}

We then examined the radial migration pattern out of the SVZ into the overlying tissue in the same sagittal sections as studied above. A radial stream of labeled cells from the SVZ into the white matter was only seen in the vicinity of the injection site, along a coronal plane (Fig. $2 A, B$, caudal injection, arrows, Fig. 4, middle injection). Outside of this limited area, no labeled cells migrated out of the SVZ. Thus, despite the full rostrocaudal migration within the SVZ, radial emigration of the labeled cells occurred only in a coronal plane at the level of injection. Stated another way, those progenitors that migrated rostrally through the SVZ never exited from the SVZ until they reached the olfactory bulb. Horizontal sections also demonstrated the emigration of labeled cells from the SVZ into the adjacent striatum and white matter only at the injection level (Fig. 3, arrows).

\section{Progenitors spread rostrocaudally in the overlying white matter}

Having emigrated into the white matter, progenitors accumulated in a dense band (Figs. $2 A, 4 B$, arrow). The accumulation expanded tangentially between 3 and $5 \mathrm{dpi}$, preferentially in the caudal direction (Fig. 2, compare $A, B$ ). From this accumulation, many progenitors migrated radially toward the pial surface (Fig. $2 B$ ). Outside of the injection level, the corpus callosum lying between this cell accumulation and the SVZ contained many fewer labeled cells (Fig. $2 B$, inset)

We studied cell migration into the white matter in more detail by comparing the early migration pattern at $1 \mathrm{dpi}$ to that at $3 \mathrm{dpi}$ on the same sagittal levels (four hemispheres from two pups). In all samples, radial migration was already apparent by $1 \mathrm{dpi}$, with cells reaching as far as the white matter and into the cortex (Fig. $4 A$; medial sagittal section at the level of the septal nuclei and RMS). By 3 dpi, however, whereas the cell accumulation layer in the white matter (Fig. $4 B$, arrow) had spread in rostral and caudal directions, direct emigration from the SVZ remained relatively confined to the locus around each injection site (Fig. $4 B$, which represents a corresponding sagittal level to that in Fig. 4A).

\section{Glial progenitors migrate out of the anterior SVZ into the frontal lobe}

Because of the restricted primary radial emigration of the progenitors from the SVZ and the predominantly caudal expansion in the white matter, neither caudal nor middle injections resulted in labeled cells colonizing the frontal white matter and cortex. Previous studies have implicated the rostral region of the SVZ to generate only olfactory interneurons (Luskin et al., 1993, 1997). Then, from where would glia that colonized in the frontal cortex originate? To address this question, we examined migration pat- 


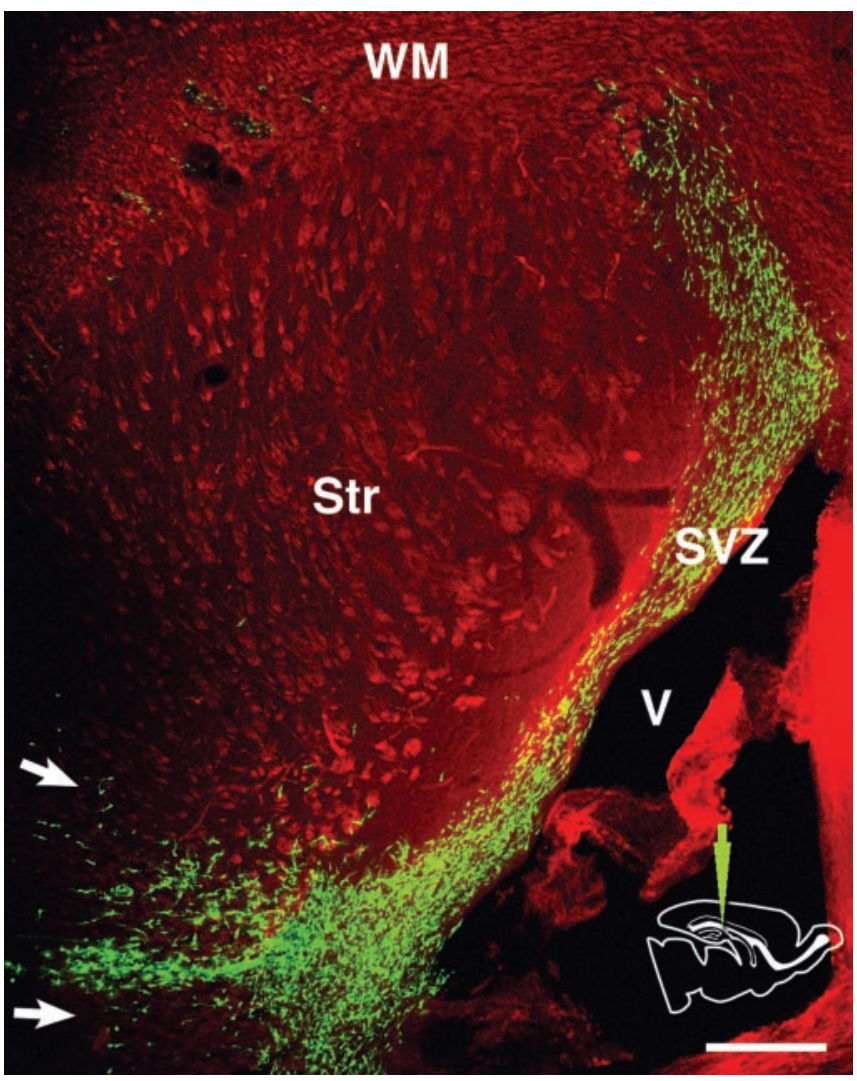

Figure 3. Distribution of labeled cells in a horizontal vibratome section $3 \mathrm{~d}$ after a caudal injection. The section is double-stained with anti-GFP ( green) and anti-phosphorylated neurofilament antibodies (red). GFP-labeled cells are primarily confined to the SVZ, showing rostrocaudal migration. They only migrate into the adjacent striatum and the white matter along a coronal plane near the injection level (arrows). V, Lateral ventricle; Str, striatum; WM, white matter; SVZ, subventricular zone. Scale bar, $300 \mu \mathrm{m}$.

terns from the anterior SVZ using a rostral injection (three hemispheres from three pups and 10 hemispheres from seven pups, analyzed at 1 and $3 \mathrm{dpi}$, respectively). As expected, labeled cells within the SVZ migrated along the RMS and reached the olfactory bulb by 3 dpi. Additionally, however, many cells migrated radially out of the anterior part of the SVZ into the frontal lobe in all samples (Fig. 5A, $1 \mathrm{dpi}, B-F, 3 \mathrm{dpi}$ ). Migration in a rostromedial direction to distribute cells into the medial frontal lobe was effectively visualized with coronal ( $n=2$ of the 10 rostrally injected hemispheres) (Fig. $5 E)$ and horizontal $(n=2$ of the 10) (Fig. $5 F$ ) sections analyzed at $3 \mathrm{dpi}$. Cell migration out of the SVZ occurred anterior to the injection site, and up to the bend between the vertical and horizontal limb of the RMS (Fig. $5 D$, an asterisk indicates the bend), after which the labeled cells in the horizontal limb were confined to the RMS.

\section{Glial progenitors migrate in the direction of} vimentin-positive glial processes

As noted above, injections at different points along the rostrocaudal axis of the SVZ resulted in restricted distributions of labeled cells in the white matter and cortex, such that cells followed restricted radial migratory paths as they exited from the SVZ. To examine how this migration pattern is associated with their possible scaffold, radial glial processes, we conducted vimentinimmunohistochemistry on vibratome sections after retroviral injections ( $n=5$ after middle injection, and $n=3$ after caudal
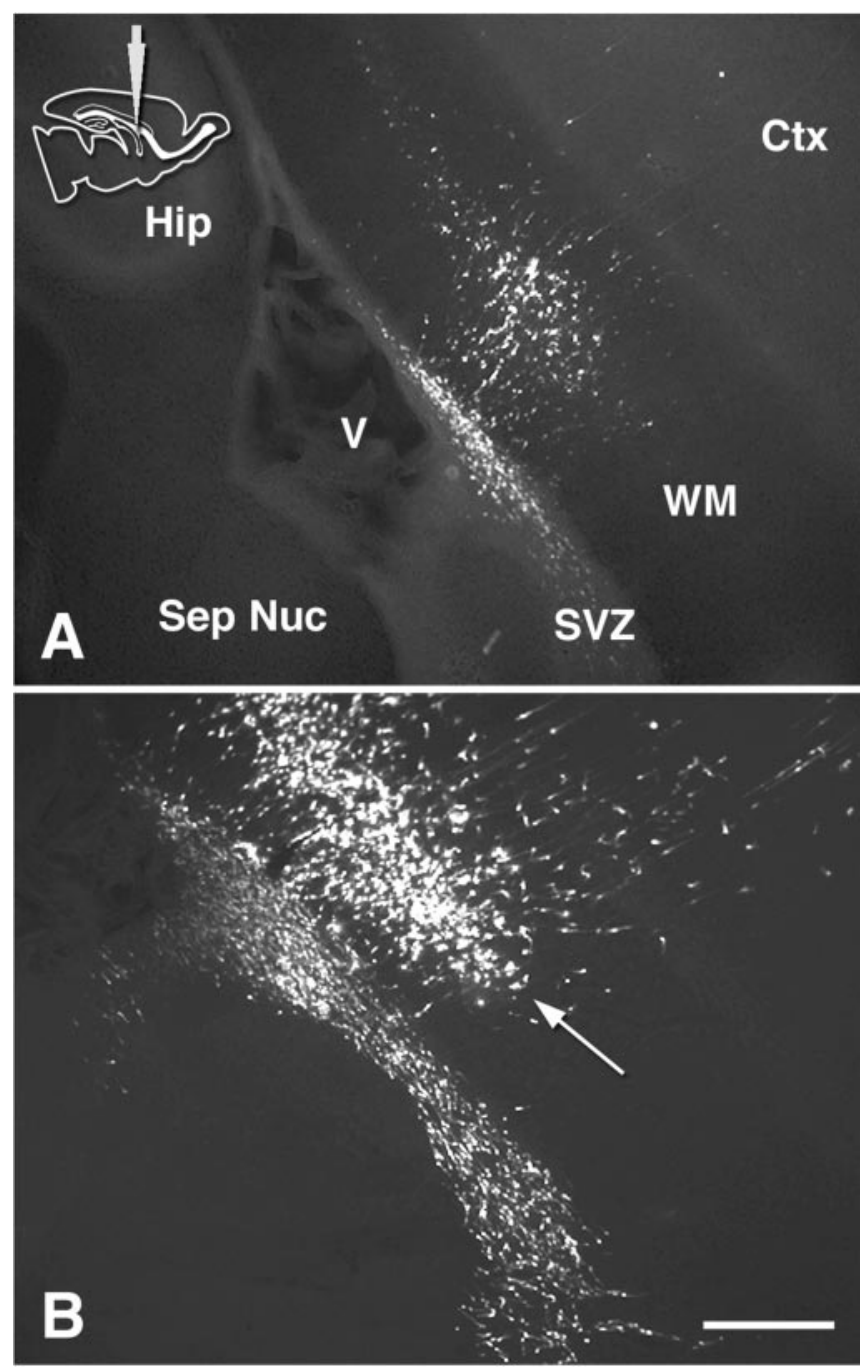

Figure 4. Distribution of GFP-labeled cells in vibratome sections at 1 and 3 dpi. Medial sagittal sections at the level of the septal nuclei and RMS $1 \mathrm{~d}(A)$ and $3 \mathrm{~d}(B)$ after "middle" injection. Arrow indicates the accumulation of labeled cells between the white matter and corpus callosum. Ctx, Cortex. Scale bar, $400 \mu \mathrm{m}$.

injection). In the sagittal plane (Fig. $6 E, F$ ), radial processes arose perpendicular to the ventricular surface, but as they approached the level between the corpus callosum and the subcortical white matter, they acutely turned caudally, especially in the caudal region, and produced a complex, dense layer (Fig. 6A,C,E, F, arrowheads). Radial fibers then exited this layer, projecting perpendicularly toward the pial surface (Fig. $6 E$, arrows). The accumulation of GFP-labeled cells in the white matter clearly overlapped this dense complex of vimentin-positive processes (Fig. $6 B$, sagittal plane, $D$, coronal plane, arrows). In hematoxylin and eosin staining of cryostat sections, this layer was observed as a layer with an increased nuclear density between the corpus callosum and the subcortical white matter in P0-P7 brains (Fig. 6G). Vimentin-immunostaining on thin cryostat sections readily depicted astrocytic cell bodies and processes densely populating this layer (Fig. $6 \mathrm{H}$ ). Because most of the GFP-labeled cells accumulating in this layer were vimentinnegative, we suggest this layer is composed of both astrocytic and oligodendrocytic progenitors.

The frontal region of the telencephalon did not show this dense layer of vimentin-positive processes but rather a straight 

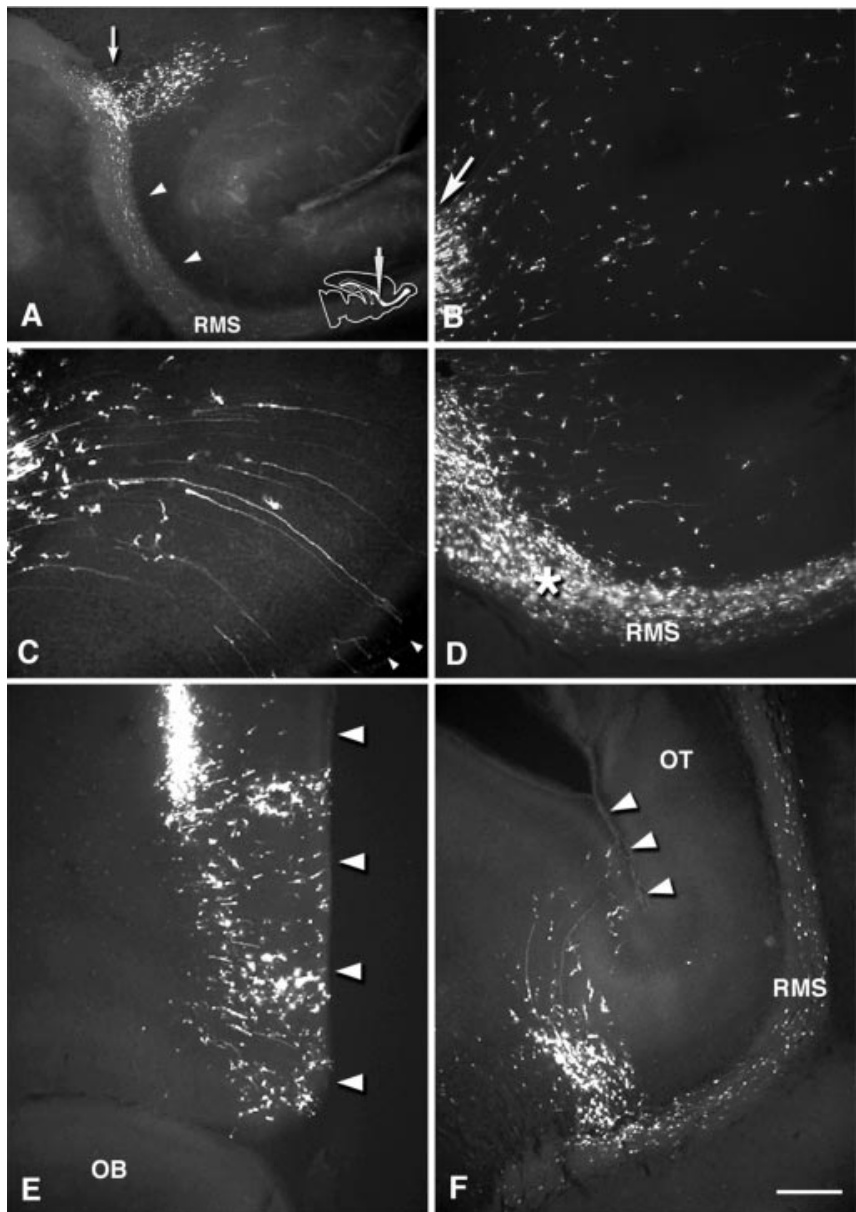

Figure 5. Distribution of GFP-labeled cells in vibratome sections 1 and $3 \mathrm{~d}$ after rostral injection. Medial sagittal section at the septal nuclei level $(A-D)$, a coronal section at the injection level $(E)$, and a horizontal section containing the RMS $(F) . A, 1$ dpi. Within the SVZ, labeled cells are distributed rostrally from the injection site (arrow) into the RMS (arrowheads), and cells also migrate radially into the overlying white matter and cortex. B, C, 3 dpi. Highpower field view of labeled cells in the frontal white matter and cortex. Cells migrate in a radial manner fanning out toward the pia. Arrow in $B$ indicates labeled cells migrating out of the injection site. In the inferior frontal cortex, cells show a ventrally skewed migration (C). Some cells have long radial processes, which reach the pial surface (C, arrowheads).D, High-powerfield view of the RMS. Labeled cells migrate out of the vertical limb of the RMS in a direction perpendicular to the axis of the RMS. Asterisk indicates the bend between the vertical and horizontal limbs of the RMS. From coronal $(E)$ and sagittal $(F)$ views, it is clear that the cells migrate rostromedially toward the frontal cortex. Arrowheads indicate the medial edge of the frontal lobe. RMS, Rostral migratory stream; $0 \mathrm{~T}$, olfactory tract. Scale bar: $A, 400 \mu \mathrm{m} ; B-F, 200 \mu \mathrm{m}$.

fanning-out of the fibers toward the pia (Fig. 6I). As a correlate, we did not observe an accumulation of GFP-labeled cells in the white matter in the frontal region (Fig. $5 A-C$ ). Along the vertical limb of the RMS, radial fibers ran parallel and distally to the ventricular surface to ensheath the RMS (Fig. $6 \mathrm{~J}$, arrowheads). Thus, we infer that progenitors emigrating out of the vertical limb after a rostral injection (Fig. 5D) first followed these radial fibers distally along the RMS and then turned to migrate into the frontal cortex.

A three-dimensional reconstruction of confocal images was performed to view the association of migrating cells with vimentin-positive radial fibers in more detail (Fig. $7 A-D$, movie 1, available at www.jneurosci.org). Within the SVZ away from the injection site, many of the GFP-labeled cells migrated rostrocaudally, oriented perpendicularly to radial fibers (see also Kakita and Goldman, 1999, their Fig. 7A). The arrow indicates a labeled



Figure 6. Distibution of radial glial fibers and composition of cell accumulation layer in the white matter. $A-F, I, J$, Anti-vimentin immunofluorescence in vibratome sections. In all sections, the rhodamine signal indicates vimentin. $B$ and $D$ also show GFP-positive cells. $A, B$, Lateral sagittal section at the level of the striatum $3 \mathrm{~d}$ after middle injection. A dense belt of vimentin-positive processes with a rostrocaudal spread at the level between the corpus callosum and the subcortical white matter is indicated by arrowheads. Accumulation of the GFPpositive cells overlaps with the dense layer of vimentin-positive fibers. C, D, Coronal sections at the level of the septal nuclei $3 \mathrm{~d}$ after a middle injection. A dense layer of vimentin-positive fibers and overlapping GFP-positive cell accumulation ( $B$, arrow) are appreciated at the corresponding level to that in the sagittal sections. $E, F$, Middle- and high-power field view of the course of vimentin-positive fiber projections in a medial sagittal section. $G, H$, Bright-field view of hematoxylin-eosin staining $(G)$ and vimentin-immunoperoxidase staining $(H)$ in $10-\mu \mathrm{m}$ thick cryostat sections. The cell accumulation layer is indicated by arrows. I, J, The frontal region in medial sagittal sections at the level of the septal nuclei and the RMS. Asterisk indicates the bend between the vertical and horizontal limb of the RMS. See Results for the meaning of the arrowheads. SVZa, Anterior part of the SVZ. Scale bars: A, B, $400 \mu \mathrm{m} ; C-E, 200 \mu \mathrm{m} ; F-H, 100$ $\mu \mathrm{m} ; \mathrm{l}, 300 \mu \mathrm{m} ;$ J, $50 \mu \mathrm{m}$. 

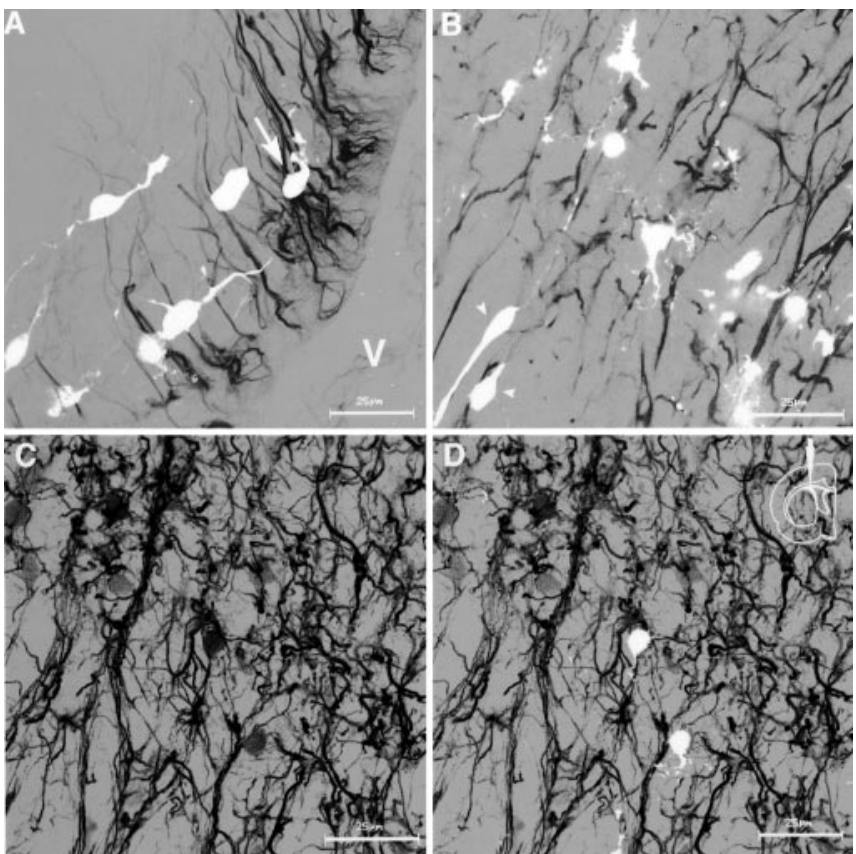

Figure 7. Three-dimensional reconstruction of confocal images of anti-vimentin (black)GFP (white) signals obtained from vibratome sections. Double-immunofluorescent images were digitally converted to gray scale mode. All figures show medial sagittal sections $3 \mathrm{~d}$ after a middle injection. A, In the SVZ, GFP-positive cells are oriented perpendicular to the vimentinpositive processes. Arrow indicates a cell that turns its process radially. Movie 1 (available at www.jneurosci.org) shows rotation of Figure $1 A$ along the $z$-axis. $B$, Transition of vimentinpositive processes from a proximal, straight form to distal, branching, and tortuous form. Ventricular surface is to the bottom left. C, D, Structure of the complex layer of the vimentin-positive processes. C, Anti-vimentin immunofluorescence. D, Superimposition of GFP-labeled cells and vimentin-positive processes. Scale bars: $A-D, 25 \mu \mathrm{m}$.
Figure 8. Time-lapse video imaging of GFP-labeled cells in living slices. A, Movie 2 (available at www.jneurosci.org), Lateral sagittal slice at the striatal level after a middle injection. The level of the slice corresponds to the sagittal section shown in Figure $3, A$ and $B$. The slice was imaged from 20 hpi (0:00) to 44 hpi (24:21). GFP-labeled cells residing in the SVZ as well as migrating radially into the overlying white matter and cortex in the vicinity of the injection site are shown. $A-1$, Time $0 \mathrm{hr} 0 \mathrm{~min}$. By this time, labeled cells are distributed in the SVZ and the overlying white matter and cortex. They are primarily confined in a coronal level near the injection site. $A-2,9 \mathrm{hr} 37 \mathrm{~min}$. Labeled cells within the SVZ have migrated rostrocaudally and expanded their distribution (compare the front of the rostrocaudal migration indicated by solid arrows in $A-1$ and $A-2$; open arrow in $A-2$ indicates the migratory front at $0 \mathrm{hr} 0 \mathrm{~min}$ ). $A-3$, Tracking lines of representative cell movements have been superimposed on the image at $24 \mathrm{hr}$ $21 \mathrm{~min}$. The starting points of each cell tracking is indicated by a green dot. Orange, Cells migrating within the SVZ. They primarily migrate rostrocaudally, however, some change direction. Arrows indicate multiple turns of a single cell. Double arrow indicates a turning point at the SVZ-white matter interface (see orange cells in $A$-4). Red, Cells radially migrating out of the SVZ into the white matter. None of them migrates in a rostrocaudal direction within the SVZ before their emigration into the white matter (see red cells in $A$-4). Cells also show radial, straight migration in the white matter. One of the tracked cells shows a ventrally oriented movement (arrowhead). Blue, Cells showing movements off the radial path. A-4, Schematic drawing of representative cell movements observed in movie 2 (available at www.jneurosci.org). B, Movie 3 (available at www.jneurosci.org), Horizontal slice at the level of the striatum $3 \mathrm{~d}$ after a caudal injection. The level corresponds to that of Figure $3 . B-1,0 \mathrm{hr} 0 \mathrm{~min}$. Labeled cells are primarily confined to the SVZ, but a few migrate in the striatum only near the injection level (arrowheads). $B-2$, Tracking lines of representative cell movements superimposed on the image at $4 \mathrm{hr}$ $24 \mathrm{~min}$. The starting points of each cell tracking is indicated by a yellow dot. Orange, Cells within the SVZ showing straight rostrocaudal migration. Green, A cell turning around within the SVZ. Blue, Cells turning at the SVZ border with the striatum. The turning points in the green and blue
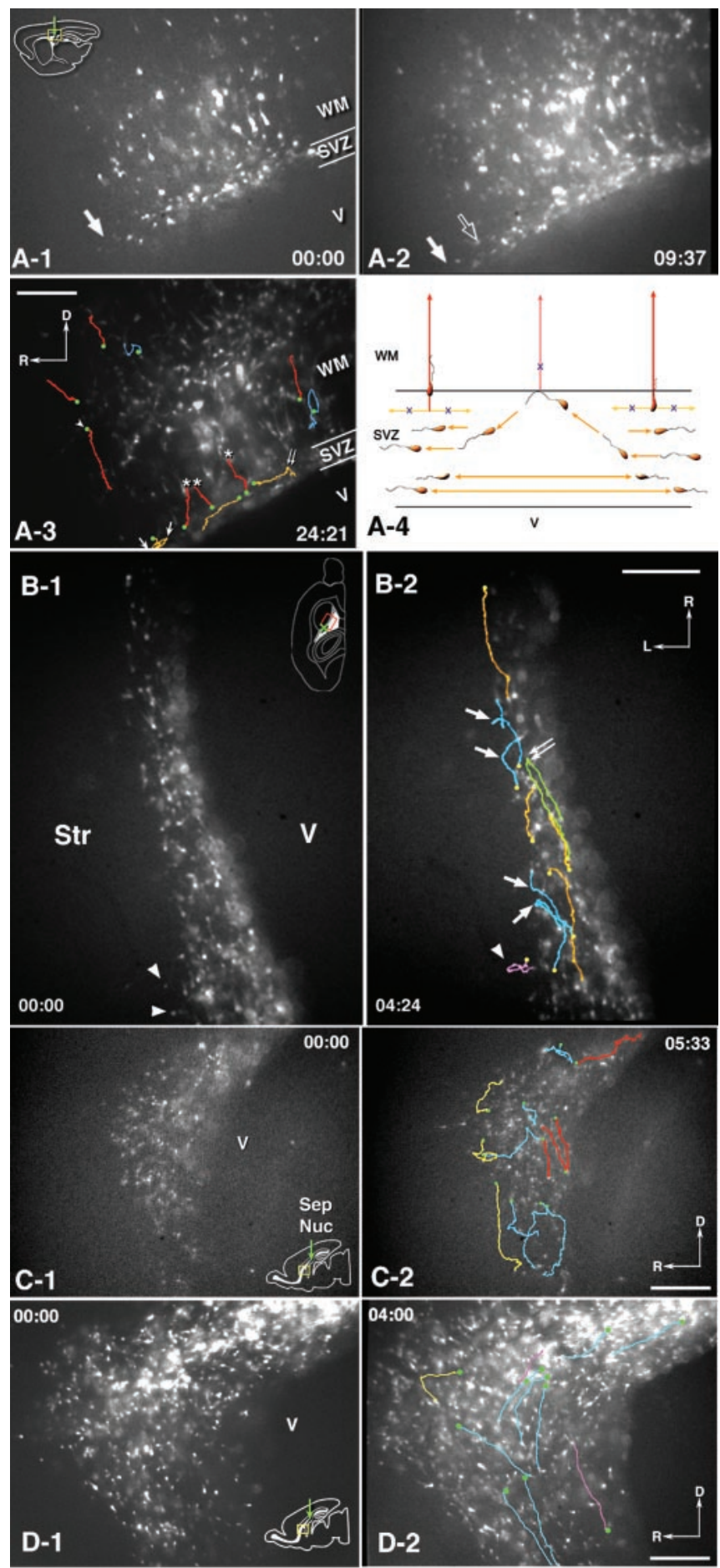

tracking are indicated by arrows. Pink, A cell migrating in the striatum. C, Movie 4 (available at www.jneurosci.org), A medial sagittal slice $3 \mathrm{~d}$ after a middle injection showing the anterior part of the SVZ and the vertical limb of the RMS (rostral to left). Labeled cells have migrated from the injection site (not appearing in this imaging field) toward the RMS. C $-1,0 \mathrm{hr} 0 \mathrm{~min} .(-2$, Tracking lines of representative cell movements superimposed on the image at $5 \mathrm{hr} 33 \mathrm{~min}$. Red, Cells migrating along the dorsocaudal to rostroventral bend formed by the SVZ and the vertical limb of the RMS. Cells show bidirectional movements. Blue, Cells changing directions in the middle of the SVZ. Yellow, Cells turning at the SVZ border with the white matter. D, Movie 5 (available at www.jneurosci.org), Cell migration in the anterior SVZ continuing into the RMS in a medial sagittal slice $3 \mathrm{~d}$ after middle injection (rostral to left). D-1, $0 \mathrm{hr} 0 \mathrm{~min}$. D-2, Tracking lines of representative cell movements superimposed on the image at $4 \mathrm{hr} 0 \mathrm{~min}$. The starting points of each cell tracking is indicated by a green dot. Blue and pink, Tangential movements. Some cells are migrating in a distal to proximal direction (pink lines). Yellow, A cell turning at the SVZ-white matter border. Scale bars, $200 \mu \mathrm{m}$. 
cell within the SVZ whose process is directed radially. Because we did not see any cells that had migrated out of the SVZ in this field, we posit this cell was not emigrating from the SVZ, but turning within the SVZ (Fig. 8A-4). Just above the SVZ, in the corpus callosum, GFP-positive cells with unipolar or bipolar morphology, characteristic of migrating cells, were closely apposed to radially arranged vimentin-positive processes (Fig. $7 B$, arrowheads at bottom left). In more dorsal white matter, where vimentin-positive processes were more branched, the GFPpositive cells showed more complicated morphologies, indicative of early differentiating glial cells (Fig. $7 B$, top and middle, $C, D)$.

\section{Video imaging reveals kinetics of neuronal and glial progenitor migration}

We performed time-lapse video imaging on living slices to examine the details of cell migration in the pathways observed in fixed tissue sections (see Kakita and Goldman, 1999 for details of process movements of individual cells). We obtained sequences from a total of 25 slices from 20 pups (from five coronal, 16 sagittal, and four horizontal slices). Coronal slices showed cell migration patterns essentially similar to those previously described (Kakita and Goldman, 1999; data not shown). We first imaged cell migration in sagittal slices at early time points after injection (Fig. $8 \mathrm{~A}$, movie 2 , available at www.jneurosci.org). At $20 \mathrm{hr}$ after injection (hpi), labeled cells were distributed around the injection level, both in the SVZ and overlying white matter (Fig. $8 A-1$, arrow indicates rostral migration front within the SVZ). However, cells within the SVZ eventually migrated to expand their distribution rostrocaudally (Fig. $8 A-2$, arrow indicates rostral migration front; open arrow indicates the front at the beginning of the imaging session). SVZ cells generally showed bidirectional, rostrocaudal movements, and many of them remained confined within the SVZ (Fig. 8A-3, orange lines). A few cells emigrated radially from the SVZ (Fig. $8 A-3$, red lines plus asterisks). Other cells turned at the SVZwhite matter border to migrate back into the SVZ (Fig. 8A-3, double arrow). Of note, we never observed cells migrating rostrocaudally within the SVZ (orange lines) that then turned and emigrated from the SVZ. Cells indicated by red lines plus asterisks in Figure 8A-3 either came in focus at the starting point of radial migration or showed a short-range, randomly oriented movement at the SVZ-white matter border before radial migration. Whereas many labeled cells in the white matter and the cortex showed a straight, radial migration (Fig. 8A-3, red lines; arrowhead indicates a cell migrating ventrally), some of them made multiple turns, migrating ventrally and/or tangentially to the ventricular surface (Fig. 8A-3, blue lines; also see Kakita and Goldman, 1999).

To study detailed behaviors of cell migration within the SVZ, we imaged horizontal slices (Fig. 8 B, movie 3, available at www.jneurosci.org). SVZ cells primarily migrated rostrocaudally along the ventricular surface and never migrated laterally into the stri-
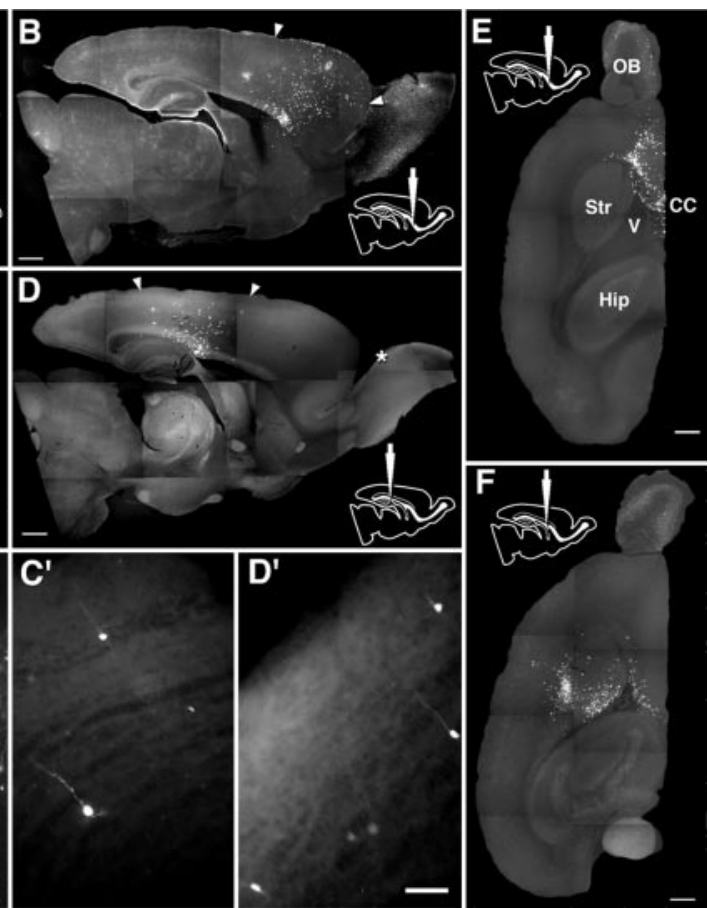

Figure 9. Final distribution of GFP-labeled cells. Sagittal vibratome sections 4 weeks after olfactory $(A), \operatorname{rostral}(B), \operatorname{middle}(C)$, GFP-labeled cells are also observed in the olfactory bulb. Asterisks in C and $D$ indicate the enlarged areas in $C^{\prime}$ and $D^{\prime}$, respectively. $\mathrm{Fr}$, Frontal lobe. Scale bars: $A-F, 1 \mathrm{~mm} ; B^{\prime}, 100 \mu \mathrm{m} ; C^{\prime}, D^{\prime}, 50 \mu \mathrm{m}$

atum, except for near the injection site (Fig. $8 B-1, B-2$, arrowheads). We also observed that cells that reached the SVZ-striatal border did not cross into the striatum, but rather turned away and migrated back into the SVZ (Fig. $8 B-2$, arrows). Some cells showed a $180^{\circ}$ turn from rostral to caudal or vice versa (Fig. 8 B-2, green line, double arrow).

We then imaged cell movements at the rostral bend of the SVZ, where the vertical limb of the RMS originates, to observe how cells enter the RMS from more proximal parts of the SVZ. Figure $8 C$, movie 4 (available at www.jneurosci.org) shows a sagittal slice $3 \mathrm{~d}$ after a middle injection. Most of the cells were migrating bidirectionally along the SVZ-RMS axis (Fig. 8C-2, red lines). Many of the cells stopped and turned at the SVZ border (Fig. 8C-2, yellow lines), whereas some changed direction within the SVZ (Fig. 8C-2, blue lines).

Figure $8 D$, movie 5 (available at www.jneurosci.org) shows another preparation around the anterior SVZ but more lateral to that in Figure $8 C$, movie 4 (available at www.jneurosci.org). Cells primarily migrated along the dorsocaudal to rostroventral bend formed by the SVZ and the vertical limb of the RMS (Fig. 8D-2, blue lines). Some cells migrated in a distal to proximal direction (Fig. $8 D$-2, pink lines). The yellow line in Figure $8 D-2$ shows a cell turning at the SVZ-white matter border.

\section{The final distribution of GFP-labeled cells reflects their earlier migratory patterns}

We studied the distribution of labeled SVZ cells 4 weeks after each injection to examine whether the final distribution of the progenitors reflected the restricted radial migration pattern we observed at early times after injection. The final distribution after each injection retained the earlier distribution patterns specific to each injection site, both in sagittal and horizontal sections (Fig. 9B-F). 

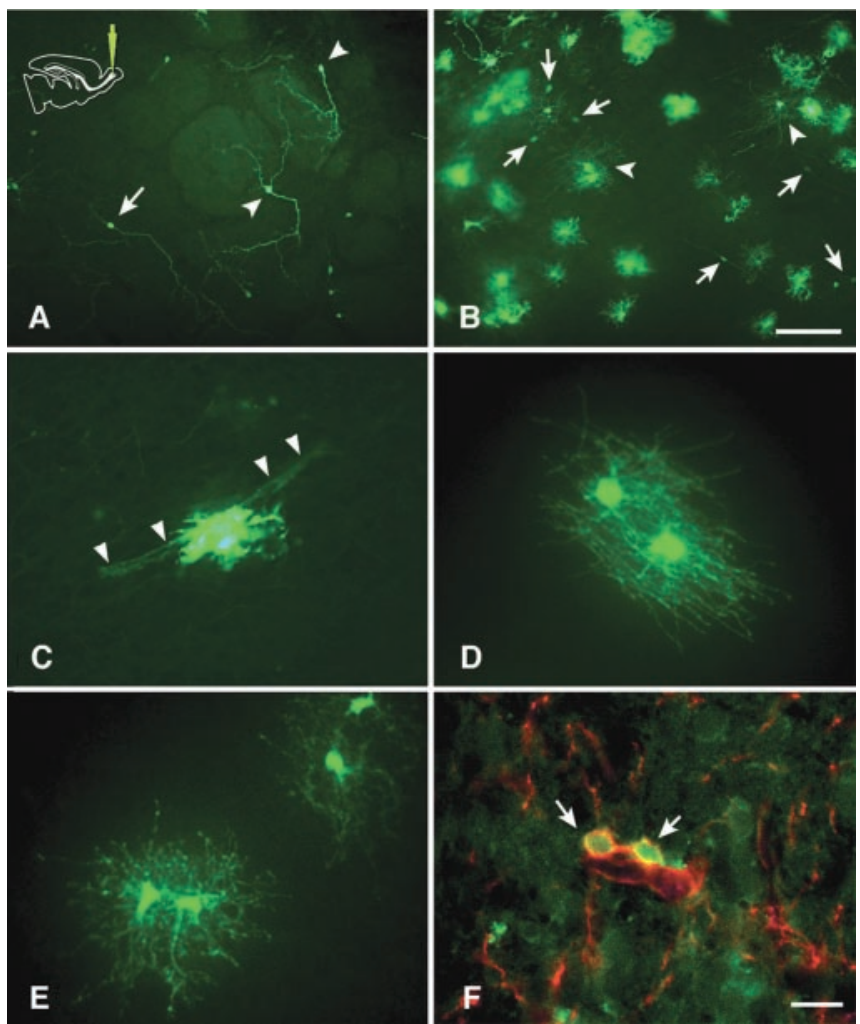

Figure 10. GFP-labeled cells in vibratome sections 4 weeks after an olfactory injection. $A$, periglomerular (arrowheads) and granular (arrow) interneurons in the olfactory cortex. $B, 01$ factory cortex-white matter interface. Many labeled cells with morphologies compatible with glia are observed. Arrowheads indicate myelinating oligodendrocytes. Labeled neurons are indicated by arrows. C, An astrocyte with foot processes wrapping a blood vessel (arrowheads). $D$, Myelinating oligodendrocytes. $E$, Nonmyelinating oligodendrocytes. F, Some GFP-labeled cells with elaborated processes are also NG2-immunopositive (red). Scale bars: $A, B, 100 \mu \mathrm{m}$; $(-F, 25 \mu \mathrm{m}$.

As expected from previous observations (Levison et al., 1993; Zerlin et al., 1995; Kakita and Goldman, 1999), after each of the caudal, middle, and rostral injections, we observed GFP-positive cells in the cerebral cortex, white matter, and striatum, all of which showed morphologies compatible with oligodendrocytes and astrocytes (details not shown).

\section{Local generation of olfactory bulb glia}

After viral injections into the neocortical SVZ (Fig. 9 $B^{\prime}, C^{\prime}$ ), GFPpositive cells that had migrated into the olfactory bulb appeared to be periglomerular and granular interneurons, but none were glia. This observation supports previous findings that the olfactory bulb contains intrinsic glial progenitors during embryogenesis independent of a cell supply from the RMS (Reid et al., 1999; Spassky et al., 2001). However, it is not clear whether the olfactory bulb continues to generate glia locally in the postnatal period and whether their final distribution is restricted to the olfactory bulb. To address this question, we injected the retrovirus directly into the six olfactory bulbs of three pups and examined the differentiation and distribution of GFP-labeled cells. We found many GFP-positive cells with morphologies compatible with glial cells, such as astrocytes, myelinating and nonmyelinating oligodendrocytes (Fig. 10C-E, respectively) as well as neurons (Fig. $10 A, B$, arrows). Some of the cells showed glial marker expression such as GFAP (data not shown) and NG2 (Fig. 10F). After olfactory bulb injection, although a few GFP-positive oligodendro- cytes and astrocytes appeared more proximally in the olfactory tract (data not shown), no labeled cells were observed in the neocortex (Fig. 9A).

\section{Discussion}

\section{Long distance migration of progenitors within the} neonatal SVZ

Dividing neuronal progenitors migrate from the SVZ into the olfactory bulb, where they differentiate into interneurons, in both the neonatal and adult CNS (Luskin, 1993; Lois and Alvarez-Buylla, 1994). The source of these neurons has been thought to be the anterior aspect of the SVZ, called the "SVZa," which lies anterior to the frontal tip of the lateral ventricle and just above the vertical limb of the RMS (Luskin, 1993; Luskin et al., 1997). However, in the juvenile and adult mouse forebrain, Doetsch and Alvarez-Buylla (1996) described a tangential, anastomosing network of chains of neuronal progenitors throughout the lateral wall of the lateral ventricle, extending from the caudal reaches of the SVZ to the rostral, SVZa area. Our observations indicate that in the neonate, this neurogenic stream appears to be composed of migratory cells densely covering the wall of the lateral ventricle, forming the dorsolateral and striatal SVZ and continuing into the RMS (Fig. 11). It would seem likely that the network of progenitors in the adult is derived from this extended migratory stream existing in the neonatal period.

However, previous studies of cell migration from regions of the SVZ caudal to its most anterior extent did not show such long distance migration along the rostrocaudal axis, but rather showed a radial migration of progenitors into the white matter and cortex, where they developed into glia (Levison et al., 1993; Luskin and McDermott, 1994; Zerlin et al., 1995). We do not know exactly why we previously failed to notice both migratory paths after viral injection at more caudal levels, but the reason may have to do with virus titers. We used lower titers in previous work $\left(10^{4}-10^{5}\right.$ vs $\left.10^{6} \mathrm{cfu} / \mathrm{ml}\right)$. Indeed, when we diluted the GFP-retroviral stock used in the current studies by tenfold, we again observed that the labeled cells migrated predominantly radially, and fewer migrated rostrocaudally (our unpublished observation). A preferential labeling of glial progenitors with a lower titer virus could arise if the glial progenitor population were larger than the neuronal progenitor population or cycled more rapidly, or if a larger proportion of glial progenitors were cycling at the time of viral injection. There is little direct evidence at present to support such potential differences, although Menezes et al. (1998) noted that those cycling progenitors labeled with BrdU after short survival preferentially resided at the periphery of the SVZa, rather than in the central zone.

Video imaging of slices revealed a bidirectional migration of progenitors in this long, rostrocaudal stream. Most migrated in a rostral direction, but some turned $180^{\circ}$. Some of the cells that migrated in this pattern did not remain strictly tangential in direction, but turned to migrate toward the SVZ edge at an oblique angle. In all such cases, the leading process of these cells stopped at the border of the SVZ and white matter and turned back into the SVZ. We never observed cells migrating rostrocaudally that subsequently turned $90^{\circ}$ to emigrate radially from the SVZ. This observation indicates some structural and/or chemical boundary between the SVZ and adjacent structures that restricts neuronal progenitor migration (Faissner and Steindler, 1995; Gates et al., 1995). The observation also implies a fundamental difference between glial and neuronal progenitors, such that the former can emigrate out of the SVZ, whereas the latter cannot. The ability to 
emigrate radially may depend on the ability to migrate along radial glial processes (also see below).

\section{Radial emigration of glial progenitors from the SVZ and the distribution of radial glia}

Progenitors that developed into astrocytes and oligodendrocytes in the surrounding gray and white matter migrated radially into the overlying white matter along a plane perpendicular to the rostrocaudal axis of the SVZ, as noted previously (Levison et al., 1993; Luskin and Boone, 1994; Kakita and Goldman, 1999). This radial emigration took place approximately in a coronal plane around the point of viral injection. After leaving the SVZ, progenitors accumulated densely forming a distinct layer between the corpus callosum and the subcortical white matter. Because glial progenitors continue to divide as they migrate, the accumulation most likely represents both migration and proliferation.

The finding that labeled cells were observed in the white matter and cortex as early as $1 \mathrm{dpi}$ (Fig. $4 A$ ) and they migrated bidirectionally (Fig. $8 A$ ) raises the possibility that we had placed the virus in the white matter or the cortex and that labeled cells had migrated ventrally into the SVZ and then had spread rostrocaudally within it. However, we think this is not likely the case for the following reasons: (1) We confirmed the injection site by identifying the densest GFP-labeled spot in serial sections or slices in each sample and analyzed only those that had the densest labeling within the SVZ. When the densest labeling was found in the white matter, few labeled cells were observed in the SVZ (data not shown). (2) In video images, we never noted a single cell radially migrating back from the white matter into the SVZ, then turning and migrating rostrocaudally.

The migration patterns of glial progenitors was closely associated with the pattern of vimentin-positive radial glial processes, supporting the possible role these processes have in providing a pathway for progenitor migration (Zerlin et al., 1995). Of note, the accumulation of GFP-labeled cells in white matter corresponded to a dense layer of branched vimentin-positive processes (Figs. 6, 7). Such branching of radial glial processes has been noted before and thought to correspond to a step in the astrocytic differentiation of radial glia (Takahashi et al., 1990). This dense layer of labeled progenitors may also correspond to a band of premyelinating oligodendrocytes, observed in a transgenic mouse in which GFP is driven by the proteolipid protein promoter (Mallon et al., 2002). Astrocytes at the junction of gray matter and corpus callosum in the early postnatal rat forebrain express GRO-1, a CXC family chemokine known to promote oligodendrocyte precursor proliferation in the spinal cord (Robinson et al., 1998). This GRO-1 "band" overlaps with the distribution of PDGF $\alpha$ receptor-positive oligodendrocyte precursors (Robinson and Franic, 2001). We have not characterized the GFP-labeled cells in this accumulation further, except to note

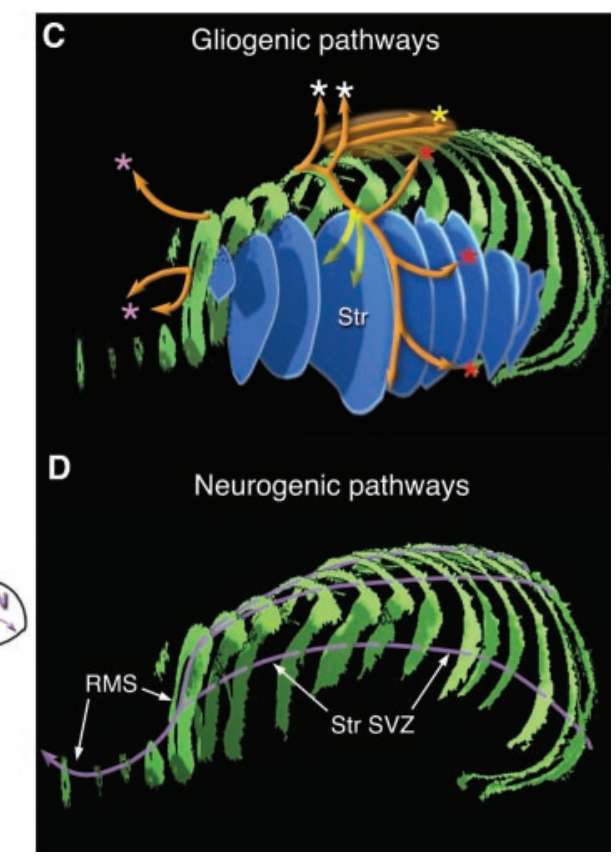

Figure 11. Models of migratory pathways of postnatal SVZ cells. $A$, Coronal plane. Migratory pathways of glial progenitors into ertex and the striatum are shown by orange and yellow arrows, respectively. Neuronal progenitors in the (he SVZ (green), the striatum (blue), and corresponding migration routes of glia progenitors to those shown in $B$. Migration toward the dorsal cortex (white asterisks), lateral cortex (red asterisks) and frontal cex (pink asterisks) are shown. Yellow arrows indicate migration into the striatum. The orange ellipsoid shadow shows the cell accumulation layer between the corpus callosum and the subcortical white matter. D, Reconstruction of the SVZ (green) and migratory pathway of neuronal progenitors shown in $A$ and $B$. G, Pathway of glial progenitors; $N$, pathway of neuronal progenitors.

that they are vimentin-negative, but we know that almost all of the SVZ cells that settle in the white matter differentiate into oligodendrocytes (Levison et al., 1993).

Taken together, we suggest that a proportion of glial progenitors that emigrate on radial glia into the white matter remain in the white matter, correlating with the complexity of astrocytic processes and high GRO-1 concentration, whereas others migrate through the white matter to develop into cortical glia. Thus, astrocytes may play an important role in the proliferation and migration of oligodendrocyte progenitors in the developing white matter through both structural and chemical mechanisms.

It is worth keeping in mind that in neonatal brains, the course of radial glial processes is largely skewed away from the coronal and sagittal planes. During their course of projection from the VZ toward the cortex crossing the SVZ and white matter, radial processes turn mediolaterally, drawing S-shapes (Misson et al., 1988; Gadisseux et al., 1989), and, at the same time, they are skewed rostrocaudally (Fig. 6E,F). This course of radial glial processes might explain some of our observations. First, in video imaging sagittal sections of the SVZ, we did not observe cells that converted from a tangential to a radial pattern. Instead, we observed that cells that emigrated radially came into focus at the starting point of their radial migration (Fig. $8 \mathrm{~A}-2$, movie 2, available at www.jneurosci.org). This suggests that these glial progenitors do not migrate rostrocaudally but may migrate mediolaterally (in a coronal plane and thus perpendicular to the sagittal plane) along radial fibers before emigrating from the SVZ. Second, we ob- 
served in sagittal sections relatively few labeled cells in the corpus callosum outside of the injection level (Fig. $2 B$, inset), despite the extensive rostrocaudal cell accumulation just dorsal to this. This suggests that the labeled cells had migrated along the caudally skewed course of the radial fibers (Fig. 6E,F) while they were crossing the corpus callosum.

\section{Bidirectional movement of the progenitors were seen both in the neurogenic and gliogenic migratory paths}

Figures 2 and 4 show that over time, the overall distribution of labeled cells expanded dorsally into the white matter and cortex, and cells within the SVZ expanded their distribution rostrally more than they did caudally. We thus assume that the overall migration is directed so that glial progenitors emigrate into the adjacent structures while neuronal progenitors eventually reach the olfactory bulb. Nevertheless, video imaging showed bidirectional cell movement of individual cells both within the SVZ and among cells migrating radially outside of the SVZ; that is, individual cells migrated either rostrally or caudally in the former, whereas they migrated either away from or back toward the SVZ in the latter (see also Kakita and Goldman, 1999, their Figs. 6 and 11). Some cells turned in direction during imaging. One possibility is that this was an artificial, abnormal migration pattern caused by disruption of directional gradients of guidance molecules by the slice preparation. Indeed, Murase and Horwitz suggested that Deleted in Colorectal Carcinoma and various integrins mediate unidirectional movement of migrating neuroblasts in the RMS (Murase and Horwitz, 2002). However, it seems unlikely that the bidirectional movement is entirely a slice artifact. Thus, in tissues that were injected first into the SVZ in vivo with the GFP retrovirus and then fixed without previous culture or imaging of slices, we have always noted that some cells show leading processes oriented caudally within the rostrocaudal migratory path. Also in the white matter and cortex in fixed tissues, we have always observed cells with leading processes oriented back toward the SVZ. If we assume that the cells migrate in the direction of their leading processes, findings in fixed tissues indicate that bidirectional movements normally occur in living brains. Stated another way, individual cells in each path may be capable of migrating against the direction of the overall migratory stream, at least transiently, before they reach the horizontal part of the RMS, where Murase and Horwitz (2002) observed more unidirectional, rostrally oriented migration. This directionality along the course of the RMS may reflect molecular gradients that guide neuroblasts toward the olfactory bulb, including both attractants and repellents (Wu et al., 1999; Murase and Horwitz, 2002).

\section{Are there (at least) two distinct populations of migratory progenitors in the SVZ?}

We noted that progenitors migrating through the SVZ in a tangential direction did not turn radially and emigrate from the SVZ at points away from the site of retroviral introduction, despite the presence of radial glial processes emanating from the SVZ at all points up to the RMS (Fig. $11 \mathrm{~B}$ ). This observation argues for two populations of progenitors: one that migrates tangentially and does not emigrate from the SVZ until the cells reach the olfactory bulb, where they differentiate into interneurons, and another that does not migrate tangentially within the SVZ but emigrates radially from the SVZ to develop into glia. It is not likely that all the SVZ cells simply have an equal chance to undergo radial emigration, because if it were, we would expect to see some of the tangentially migrating progenitors emigrate radially at all points along the rostrocaudal axis. It is also unlikely that this restricted radial migration results from breakage of migration boundary or reaction against tissue damage caused by the injection itself, for several reasons. First, we assume that glial progenitors emigrate from the SVZ at all points to give rise to white matter and cortical glia (Altman and Bayer, 1990). However, none of the rostrocaudally migrating progenitors emigrated from the SVZ to become glia at points away from the injection level. Second, we only rarely see labeling along an injection track (Levison et al., 1993), and we have observed the same migration patterns after injecting virus from the lateral aspect of the brain as we see after a dorsal injection (our unpublished observation). Third, the track itself seems not to influence the direction of glial progenitor migration. For example, many of the SVZ cells migrate laterally through white matter away from the injection site and then radially into the cortex (Zerlin et al., 1995; Kakita and Goldman, 1999). The rostral injection resulted in a fanning migration of the labeled cells into the frontal cortex, also in a direction away from the injection track.

How or if these two progenitor populations are closely connected by lineage is not clear, although single SVZ cells, labeled by retrovirus in vivo, can give rise to clones containing both neurons and glia in vitro (Levison and Goldman, 1997), suggesting that at least some of the progenitors are multipotent. In addition, one could posit other populations in the SVZ, which might give rise to migratory neuroblasts and glioblasts. We are currently attempting to define different cell populations and their distributions within the SVZ based on proliferation rates and the expression of lineage-related markers such as proneural genes.

\section{References}

Altman J, Bayer SA (1990) Horizontal compartmentation in the germinal matrices and intermediate zone of the embryonic rat cerebral cortex. Exp Neurol 107:36-47.

Altman J, Bayer SA (1995) Atlas of prenatal rat brain. Boca Raton, FL: CRC. Bayer SA, Altman J, Russo RJ, Dai XF, Simmons JA (1991) Cell migration in the rat embryonic neocortex. J Comp Neurol 307:499-516.

de Carlos JA, Lopez-Mascaraque L, Valverde F (1996) Dynamics of cell migration from the lateral ganglionic eminence in the rat. J Neurosci 16:6146-6156.

Doetsch F, Alvarez-Buylla A (1996) Network of tangential pathways for neuronal migration in adult mammalian brain. Proc Natl Acad Sci USA 93:14895-14900.

Faissner A, Steindler D (1995) Boundaries and inhibitory molecules in developing neural tissues. Glia 13:233-254

Gadisseux JF, Evrard P, Misson JP, Caviness VS (1989) Dynamic structure of the radial glial fiber system of the developing murine cerebral wall. An immunocytochemical analysis. Brain Res Dev Brain Res 50:55-67.

Gates MA, Thomas LB, Howard EM, Laywell ED, Sajin B, Faissner A, Gotz B, Silver J, Steindler DA (1995) Cell and molecular analysis of the developing and adult mouse subventricular zone of the cerebral hemispheres. J Comp Neurol 361:249-266.

Kakita A, Goldman JE (1999) Patterns and dynamics of SVZ cell migration in the postnatal forebrain: monitoring living progenitors in slice preparations. Neuron 23:461-472.

Levison SW, Goldman JE (1997) Multipotential and lineage restricted precursors coexist in the mammalian perinatal subventricular zone. J Neurosci Res 48:83-94.

Levison SW, Chuang C, Abramson BJ, Goldman JE (1993) The migrational patterns and developmental fates of glial precursors in the rat subventricular zone are temporally regulated. Development 119:611-622.

Lois C, Alvarez-Buylla A (1994) Long-distance neuronal migration in the adult mammalian brain. Science 264:1145-1148.

Luskin MB (1993) Restricted proliferation and migration of postnatally generated neurons derived from the forebrain subventricular zone. Neuron 11:173-189.

Luskin MB, Boone MS (1994) Rate and pattern of migration of lineally- 
related olfactory bulb interneurons generated postnatally in the subventricular zone of the rat. Chem Senses 19:695-714.

Luskin MB, McDermott K (1994) Divergent lineages for oligodendrocytes and astrocytes originating in the neonatal forebrain subventricular zone. Glia 11:211-226.

Luskin MB, Parnavelas JG, Barfield JA (1993) Neurons, astrocytes, and oligodendrocytes of the rat cerebral cortex originate from separate progenitor cells: an ultrastructural analysis of clonally related cells. J Neurosci 13:1730-1750.

Luskin MB, Zigova T, Soteres BJ, Stewart RR (1997) Neuronal progenitor cells derived from the anterior subventricular zone of the neonatal rat forebrain continue to proliferate in vitro and express a neuronal phenotype. Mol Cell Neurosci 8:351-366.

Mallon BS, Shick HE, Kidd GJ, Macklin WB (2002) Proteolipid promoter activity distinguishes two populations of NG2-positive cells throughout neonatal cortical development. J Neurosci 22:876-885.

Marshall JJ, Saeed Z (2002) After effects 5 bible. New York: Hungry Minds.

Menezes JR, Dias F, Garson AV, Lent R (1998) Restricted distribution of S-phase cells in the anterior subventricular zone of the postnatal mouse forebrain. Anat Embryol (Berl) 198:205-211.

Misson JP, Edwards MA, Yamamoto M, Caviness VS Jr (1988) Identification of radial glial cells within the developing murine central nervous system: studies based upon a new immunohistochemical marker. Brain Res Dev Brain Res 44:95-108.

Misson JP, Austin CP, Takahashi T, Cepko CL, Caviness VS Jr (1991) The alignment of migrating neural cells in relation to the murine neopallial radial glial fiber system. Cereb Cortex 1:221-229.

Murase S, Horwitz AF (2002) Deleted in colorectal carcinoma and differen- tially expressed integrins mediate the directional migration of neural precursors in the rostral migratory stream. J Neurosci 22:3568-3579.

Reid CB, Liang I, Walsh CA (1999) Clonal mixing, clonal restriction, and specification of cell types in the developing rat olfactory bulb. J Comp Neurol 403:106-118.

Robinson S, Franic LA (2001) Chemokine GRO1 and the spatial and temporal regulation of oligodendrocyte precursor proliferation. Dev Neurosci 23:338-345.

Robinson S, Tani M, Strieter RM, Ransohoff RM, Miller RH (1998) The chemokine growth-regulated oncogene-alpha promotes spinal cord oligodendrocyte precursor proliferation. J Neurosci 18:10457-10463.

Spassky N, Heydon K, Mangatal A, Jankovski A, Olivier C, Queraud-Lesaux F, Goujet-Zalc C, Thomas JL, Zalc B (2001) Sonic hedgehog-dependent emergence of oligodendrocytes in the telencephalon: evidence for a source of oligodendrocytes in the olfactory bulb that is independent of PDGFRalpha signaling. Development 128:4993-5004.

Takahashi T, Misson JP, Caviness VS Jr (1990) Glial process elongation and branching in the developing murine neocortex: a qualitative and quantitative immunohistochemical analysis. J Comp Neurol 302:15-28.

Wu W, Wong K, Chen J, Jiang Z, Dupuis S, Wu JY, Rao Y (1999) Directional guidance of neuronal migration in the olfactory system by the protein Slit. Nature 400:331-336.

Zerlin M, Goldman JE (1997) Interactions between glial progenitors and blood vessels during early postnatal corticogenesis: blood vessel contact represents an early stage of astrocyte differentiation. J Comp Neurol 387:537-546.

Zerlin M, Levison SW, Goldman JE (1995) Early patterns of migration, morphogenesis, and intermediate filament expression of subventricular zone cells in the postnatal rat forebrain. J Neurosci 15:7238-7249. 